\title{
Teoria da Atividade: contribuições conceituais e metodológicas para o estudo da aprendizagem organizacional
}

\section{Activity Theory: conceptual and methodological contributions for studying organizational learning}

\author{
Marco Antonio Pereira Querol ${ }^{1}$ \\ Marcio Pascoal Cassandre ${ }^{2}$ \\ Yára Lúcia Mazziotti Bulgacov ${ }^{3,4}$
}

\begin{abstract}
Resumo: Atualmente existe no Brasil uma crescente discussão sobre aprendizagem organizacional na área de Administração. Desta forma, este artigo visa contribuir para essa discussão introduzindo elementos teórico-metodológicos provenientes da Teoria da Atividade, pertencente à perspectiva histórico-cultural, de tradição russa. Dentro dessa proposta, a metodologia de pesquisa de desenvolvimento do trabalho e a aprendizagem expansiva são apresentadas como elementos alinhados a essa teoria e promissores no estudo da aprendizagem e no desenvolvimento organizacional, contribuindo para a aprendizagem do nível individual e coletivo. Com base nesse escopo teórico-metodológico de pesquisa, pretende-se contribuir para novos debates, oportunizando o diálogo com outras perspectivas de análise bem como considerando a possibilidade da própria expansão do conceito sobre aprendizagem organizacional.
\end{abstract}

Palavras-chave: Teoria da Atividade. Aprendizado organizacional. Pesquisa e desenvolvimento do trabalho. Aprendizagem expansiva. Materialismo dialético.

\begin{abstract}
In accordance with the need to expand discussions on Organizational Learning in the Administration area in Brazil, as pointed out by Brazilian authors engaged in the issue, this article contributes to the introduction of ontological understandings based on dialectical materialism, and the theoretical and methodological elements of the Activity Theory, which belongs to the historical-cultural perspective of the Russian tradition. Within this proposal, Developmental Work Research and Expansive Learning are presented as promising elements aligned with this theory in the study of learning and organizational development, contributing to the extrapolation of learning at the individual and collective levels. Based on this theoretical and methodological scope of research, we intend to contribute to further discussions by providing opportunity to dialogue with other perspectives of analysis and considering the very expansion of the concept of Organizational Learning.
\end{abstract}

Keywords: Activity Theory. Organizational learning. Developmental work research. Expansive learning. Dialectical materialism.

\section{Introdução}

Atualmente no Brasil presencia-se na área de Administração uma crescente discussão e interesse sobre aprendizagem organizacional (AO). Tal discussão visa ampliar tanto a compreensão a nível teórico como prático, em um momento em que é crescente a valorização da participação dos sujeitos em alguns processos decisórios, do incentivo à criatividade deles para soluções rápidas e eficientes, além do apoio ao trabalho em equipe (FARIA, 2007).

Apesar dos avanços na compreensão do processo de $\mathrm{AO}$, ainda existem dúvidas que são expostas por autores desse campo de estudo e que neste artigo serão discutidas. Implícitos a essas dúvidas, há que se revelar um conjunto de pressupostos que orientam a produção do conhecimento no campo da

\footnotetext{
${ }^{1}$ Universidade Federal do Paraná - UFPR, Av. Prefeito Lothário Meissner, 632, Jardim Botânico, CEP 80210-170, Curitiba, PR, Brasil, e-mail: mapquero@gmail.com

2 PPA, Programa de Pós Graduação em Administração, Universidade Estadual de Maringá - UEM, CEP 87020-900, Maringá, PR, Brasil, e-mail: mcassandre@ hotmail.com

${ }^{3}$ PMDA, Programa de Mestrado e Doutorado em Administração, Universidade Federal do Paraná - UFPR, CEP 80210-170, Curitiba, PR, Brasil, e-mail: ybulgacov@gmail.com

${ }^{4}$ PMDA, Programa de Mestrado e Doutorado em Administração, Universidade Positivo - UP, CEP 81280-330, Curitiba, PR, Brasil Recebido em 1/10/2012 — Aceito em 6/1/2014
}

Suporte Financeiro: Academia da Finlândia (Academy of Finland) e Capes. 
$\mathrm{AO}$ e que levam a alguns questionamentos, como, por exemplo: (a) sobre a natureza do fenômeno da aprendizagem organizacional (ontologia); (b) sobre a forma de conhecer esse fenômeno da aprendizagem organizacional (epistemologia); e (c) sobre os caminhos, ou seja, os métodos para apreender esse fenômeno organizacional (metodologia).

Do ponto de vista ontológico há um questionamento na natureza da aprendizagem explicitado em publicações sobre essa temática. Bitencourt e Azevedo (2006) apontam a necessidade de se conhecer se a aprendizagem é cognitiva ou cultural e se é ela voltada para conhecimento tácito ou explícito. Antonello e Godoy $(2009,2010)$ indagam se a aprendizagem nas organizações está associada a um resultado que se pretende alcançar nas organizações. Ruas e Antonello (2003) discutem se o fato de se aprender significa necessariamente um processo de mudança, ou seja, havendo aprendizagem obrigatoriamente os sujeitos mudam as suas práticas, atitudes e comportamentos.

As questões trazidas por esses autores permitem considerar que a $\mathrm{AO}$ poderia estar se deslocando de uma concepção ontológica realista - que aceita que o mundo social é como o mundo natural - para um nominalismo - que pressupõe sempre a interpretação e construção do sujeito em relação ao mundo.

Quanto aos aspectos epistemológicos interessa-se pelo sujeito da aprendizagem; se são os indivíduos, a organização ou se são ambos que aprendem. A necessidade de expandir a unidade de análise do nível individual para o nível interpessoal (grupal, intergrupal, organizacional e interorganizacional), além do reconhecimento de quem é o agente do aprendizado, é refletida também nos trabalhos de Antonello e Godoy (2010), Ruas e Antonello (2003) e Bitencourt e Azevedo (2006).

Em se tratando da perspectiva metodológica que envolva a $\mathrm{AO}$, considera-se o desafio de ampliar a forma de apreendê-la, considerando o alcance tanto da aprendizagem como também da mudança, lembrando, inclusive, da existência do elemento "conflito", assumindo que as organizações não possuem ambientes totalmente controlados e estáveis e não estão livres de controvérsias, oposições, desacordos etc. Ao expandir essa compreensão metodológica pode-se provocar a identificação do quanto a aprendizagem pode ser descritiva ou prescritiva e das possibilidades de se fazer a sua gestão (BITENCOURT; AZEVEDO, 2006).

Na pensata intitulada $O$ futuro da aprendizagem organizacional: possibilidades e desafios, publicada por Bitencourt e Azevedo (2006, p. 110-111), as autoras apontam que a AO demanda "[...] novas e diversas interpretações de eventos e situações [...]" com vistas a explicitar os paradoxos e as contradições da abordagem. Para tanto, sugerem a compreensão dos "processos de aprendizagem", construídos historicamente pelas experiências e situações peculiares a cada organização em particular, implicando repensar a AO apenas como um modelo de gestão. Essas sugestões apresentadas indicam um caminho em direção contrária à hegemonia das perspectivas predominantes, de forte influência, da abordagem da administração científica tradicional, cuja ênfase recai sobre a importância do pensamento sistêmico e da melhoria contínua (ANTONELLO; GODOY, 2009, 2010).

As questões que desafiam a $\mathrm{AO}$ refletem a limitação ou falta de uma abordagem teórico-metodológica sólida que integre os diferentes aspectos relacionados à aprendizagem, desde questões epistemológicas e ontológicas até os métodos de como proceder à aprendizagem. A proposta deste artigo visa contribuir para o debate sobre essas limitações e para a ampliação do entendimento sobre a AO.

Para tanto, considera-se a Teoria da Atividade como uma alternativa teórico-metodológica para o estudo e o desenvolvimento da aprendizagem em organizações, objetivando introduzir, além dessa teoria, a metodologia de pesquisa de desenvolvimento do trabalho como potenciais abordagens teóricometodológicas para o estudo da aprendizagem e do desenvolvimento organizacional, de forma a inspirar novas perspectivas de análise do fenômeno e, por sua vez, expandir o conceito (VIRKKUNEN, 2009).

$\mathrm{O}$ artigo começa com a apresentação da visão dialética das transformações organizacionais, introduzindo princípios ontológicos da dialética materialista nos quais a Teoria da Atividade se baseia. Em continuação, apresenta-se o desenvolvimento dos principais conceitos teóricos utilizados na Teoria da Atividade: inicialmente o conceito de atividade proposto por Marx, a teoria de mediação da ação humana proposta por Vygotsky e o conceito de atividade coletiva proposto por Leontyev. Os modelos de um sistema de atividade e do ciclo de desenvolvimento expansivo desenvolvidos por Engeström, com base nos trabalho dos autores anteriormente mencionados, são incluídos neste trabalho. Na sequência aborda-se sobre a Teoria da Aprendizagem Expansiva e a metodologia de pesquisa e desenvolvimento do trabalho. Por fim, insere-se um diálogo entre as sugestões de debate trazidas pelos autores da $\mathrm{AO}$ e as propostas oferecidas pela TA abordadas neste artigo.

\section{Uma visão dialética de transformações organizacionais}

Conforme Benson (1983), os estudos sobre as organizações complexas se apoiaram numa sucessão de teorias racionais e funcionalistas e numa metodologia positivista. Os princípios ontológicos da dialética materialista são aqui apresentados como uma sugestão 
de solução para as limitações e dilemas relacionados ao dualismo entre construtivismo versus positivismo.

Nessa proposta, considera-se a diferenciação oferecida por Davydov (1990) (VIRKKUNEN; SHAUPP, 2011; VIRKKUNEN; RISTIMÄKI, 2012) entre dois tipos de generalização: generalização abstrato-empírica e generalização teórico-genética. A primeira refere-se a generalizações produzidas por meio de relações de causa-efeito, as quais são usadas para produzir efeitos esperados e criar causas desejáveis. Pesquisas baseadas nesse tipo de generalização são particularmente úteis quando a relação entre as variáveis e os fatores são estáveis e relativamente inalteradas. No entanto, essa abordagem é limitada quando as condições empíricas variam e/ ou o objeto da pesquisa em si esteja em construção ou ainda não exista.

A generalização abstrato-empírica é limitada em se tratando de situações onde os pesquisadores estão interessados não apenas nas propriedades que já existiam, mas também naquelas que poderiam ser construídas no futuro. Já o conhecimento produzido a partir da generalização teórico-genética se concentra em revelar as raízes genéticas (origem) de um fenômeno e do sistema de relações funcionais que determinam a sua ocorrência e o seu desenvolvimento. As diferenças entre esses dois tipos de generalização estão relacionadas com a sua ontologia: a compreensão de como o mundo é e se desenvolve, além da sua relação com o homem nessa existência.

$\mathrm{Na}$ ontologia dialética, a primeira suposição é que as coisas não existam a priori ou sem as suas relações, mas essas coisas são resultado da evolução em sistemas de relações. Em outras palavras, a essência das coisas é inseparável e constituída por suas relações (HEGEL, 1892 apud TOLMAN, 1981) e só pode ser compreendida no contexto de desenvolvimento de sistemas de relações, movimento e evolução.

Tolman (1981) considera que a compreensão da dialética pressupõe a análise de quatro elementos: relações internas, movimento, contradição e desenvolvimento. Para ele, coisas estão constantemente mudando e evoluindo e elas não existem sem movimento. Tal movimento e evolução podem ser explicados através de contradições no seio das relações internas que constituem as coisas. Em se tratando do elemento movimento, o autor sugere que a dialética vai além do movimento externo ou mecânico, pois apenas contemplar a existência de um fenômeno não permite compreender o começo e o fim de sua existência (ENGELS, 1959 apud TOLMAN, 1981).

O outro elemento, a contradição, pode ser explicado no próprio movimento, haja vista que esse por si só é uma contradição e aquela expressa a raiz de todo movimento e vitalidade do fenômeno. Dessa forma a filosofia dialética não se interessa pela descoberta de oposições internas mas sim em fornecer uma forma racional de lidar com elas que seja ao mesmo tempo essencial para o objeto e capaz de compreender a sua função em automovimento.

Por sua vez, o desenvolvimento sob o ponto de vista da dialética é a forma mais elevada de movimento, que se originou em contradições internas à coisa em desenvolvimento.

Desenvolvimento é a luta dos contrários. O que leva ao desenvolvimento de algo é o negativo que possui dentro de si mesmo, é isso que constitui a verdadeira dialética" (TOLMAN, 1981, p. 39).

Desenvolvimento não significa o mesmo que crescimento - que carrega consigo a ideia de mudança quantitativa - mas refere-se a uma mudança qualitativa.

Dessa forma, a ontologia dialética pode ensejar aos pesquisadores em gestão organizacional não apenas a identificação e descrição de fatores que afetam a gestão e a relação entre eles, mas também explicar por que novas práticas emergem. Nesse contexto, a relação do fenômeno e os sujeitos deve ser contemplada dentro de um escopo teórico capaz de refletir esse entendimento de construção ativa, amalgamada dentro das relações em constante movimento entre os sujeitos nas suas relações.

Baseado na dialética materialista, Ilyenkov (1982) argumenta que um novo fenômeno surge como uma anomalia e uma exceção. A tarefa do estudo de um fenômeno consiste em descobrir a primeira ocorrência, identificando o novo princípio em que o sistema é baseado, ou seja, a "célula germinal" que é um princípio realizado através de uma configuração específica de relações. A nova estrutura ou princípio emerge primeiramente como um caso isolado, único, tornando-se posteriormente algo geral. Esse método consiste de dois processos: primeiro, a redução do concreto - a totalidade sensorial que é diretamente observável - em uma abstração inicial (um célula germinal, um princípio geral), e, em segundo lugar, a derivação do abstrato para uma forma concreta de manifestação. Davydov (1990, p. 281-282) desenvolveu esse método propondo três etapas para a criação de generalizações teórico-genéticas: (a) identificar as contradições a serem resolvidas; (b) identificar uma "célula germinal" do fenômeno; (c) testar a célula germinativa tentando desenvolvê-la na prática.

Dentro da proposta aqui defendida e corroborando Benson (1983), a teoria dialética pode explicar o fundamento empírico das teorias convencionais da organização devido a sua valorização dos processos sociais ignorados e não refletidos pelos teóricos das tais teorias da organização. Assim, contribui para acompanhar os movimentos de transformação 
constantes sofridos pelas organizações, que por sua vez são constituídas por sujeitos.

\section{Teoria da Atividade Histórico-Cultural}

Na Teoria da Atividade (TA), a aprendizagem é situada em atividades humanas. Aprendizagem enquanto sistema de determinados tipos de atividade cuja realização conduz a novos conhecimentos e práticas, cujas ocorrências são manifestadas sempre em condições sociais e históricas em que se realizam (CAMARGO, 1997). Por sua vez, a TA é uma linha teórica e de pesquisa interdisciplinar proveniente da psicologia sócio-histórica e cultural russa, iniciada nos anos 1920 e 1930 pelos psicólogos Vygostky, Luria e A. N. Leontyev (CASSANDRE; BULGACOV; CAMARGO, 2011; ENGESTRÖM; SANNINO, 2010). A TA teve início com estudos sobre o desenvolvimento de crianças e se expandiu para os estudos de atividades de trabalho, tais como serviços bancários, de saúde, trabalho legal e na agricultura.

\section{Fundamentos}

O conceito de atividade foi introduzido pelo filósofo alemão Georg W. Friedrich Hegel, que reconheceu o papel da atividade produtiva e os instrumentos do trabalho no desenvolvimento do conhecimento (ENGESTRÖM, 1987; SANNINO, 2011). Esse autor propõe que a consciência humana é formada sob a influência do conhecimento acumulado pela sociedade ao longo da história e que esse conhecimento é objetivado através da criação de artefatos pela humanidade.

As opiniões de Hegel foram desenvolvidas por Karl Marx, que considera o homem não apenas como um produto da história e da cultura, mas também como um transformador da natureza e um criador. Marx enfatiza o aspecto ativo dos seres humanos, capazes de mudar o mundo propositadamente e criar coisas novas que vão além de sua capacidade real, ao invés de simplesmente adaptarem-se às mudanças no ambiente.

Baseado no conceito de atividade de Marx (1976), Vygotsky (1978) criou a ideia da mediação cultural da ação humana, cujo conceito tornou-se central na TA. Mediação cultural significa que a relação entre o sujeito e o objeto é mediada por artefatos culturais (Figura 1). Um artefato se refere a um aspecto do mundo material (e conceitual) que tenha sido modificado ao longo da história da sua constituição através de ações (COLE, 1996, p. 117). De acordo com Cole (1996), o conceito de artefato como produto da história humana oferece uma maneira de superar a dualidade entre o interno e externo, ideal e material.

\section{O modelo básico de mediação proposto por Vygotsky}

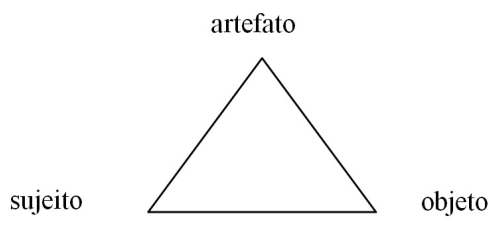

Figura 1. O modelo básico de mediação proposto por Vygotsky. Fonte: Vygotsky (1978, p. 40).

\section{Sistema de atividade como unidade de análise}

Uma limitação da proposta de Vygotsky é que a unidade de análise é focalizada apenas em indivíduos. Essa unidade de análise foi expandida por Leontyev (1981), o qual diferenciou a ação individual da atividade coletiva. Devido à divisão do trabalho, as ações dos indivíduos passaram a não satisfazer diretamente suas próprias necessidades. A satisfação das necessidades é mediada através de um processo social de distribuição do objeto coletivo. As necessidades do trabalhador tornam-se satisfeitas por uma parte dos produtos da sua atividade coletiva. Essa distribuição da ação é regulamentada por meio de relações que são específicas para cada forma histórica de produção.

A distinção entre ação e atividade é de crucial importância para a compreensão de como as ações emergem e do que as direciona. De acordo com Leontyev (1978), as ações são direcionadas a objetivos e metas. No entanto, somente o objeto da atividade coletiva - e não os objetivos das ações - pode explicar o porque de uma ação surgir. A separação entre objetivo de uma ação e objeto da atividade cria uma relação dialética; atividades não podem ser entendidas sem ações e ações não podem ser compreendidas sem atividade. (LEONTYEV, 1978, p. 64)

Em uma abordagem baseada na TA, os seres humanos são vistos como envolvidos em diversas atividades, diferenciadas pelo seu objeto. O pressuposto básico é que uma atividade é sempre dirigida a um objeto. A fim de estudar uma determinada atividade, primeiro é importante identificar o objeto que direciona as ações do sujeito (LEONTYEV, 1978, p. 62).

$\mathrm{O}$ conceito de objeto da atividade é baseado em quatro princípios. O primeiro princípio refere-se ao motivo e origem de uma determinada atividade, e a razão para sua existência está relacionada a uma necessidade que existe na sociedade (LEONTYEV, 1978, p. 62). Entre os seres humanos, as necessidades não são puramente biológicas, mas evoluem em atividades humanas e também são mediadas por artefatos que são definidos culturalmente no curso da história (LEONTYEV, 1978). Entre os humanos, 
o motivo emerge através da apropriação, uso e desenvolvimento de objetos e artefatos em atividades humanas coletivas. Assim, as pessoas se envolvem em atividades coletivas para produzir objetos que satisfaçam suas necessidades e, ao mesmo tempo, contribuam para a realização e o desenvolvimento de atividades (MIETTINEN, 2005).

O segundo princípio é que o objeto é duplo, epistêmico (ideal) e objetivo (material). O objeto de uma atividade é, portanto, tanto ideal como material, imaginado e percebido. Como Miettinen (1998) explica, o conceito de um objeto de uma atividade transcende a dualidade entre sujeito e objeto, bem como a oposição entre construtivismo e realismo. O objeto de uma atividade inclui a matéria-prima a ser transformada, assim como uma visão, um resultado ou um produto (ou serviço). A transformação não é apenas mental e discursiva, mas também objetivada em um sistema híbrido composto por seres humanos e artefatos, bem como elementos biológicos (MIETTINEN, 1998, p. 424).

O terceiro princípio é que o objeto está em constante mudança. Contrário a uma ação cujo objetivo é ancorado a um lugar e tempo, o objeto de uma atividade é mais sustentado e aberto. Essa mudança ocorre não apenas no aspecto material do objeto, mas também no seu aspecto ideal, que inclui a conceituação de uma coisa, o conhecimento dessa coisa e os métodos para produzi-la.

O quarto princípio é que o objeto só pode ser alcançado coletivamente. Nas sociedades modernas, a maioria dos objetos não podem ser produzidos por indivíduos isolados, sem a participação de outros sujeitos nos processos de produção, logo as atividades, por sua vez, são coletivas, ou seja, feitas em conjunto com outros sujeitos. Leontyev $(1978$, p. 51) propõe que a atividade tem de ser entendida em suas relações sociais. Uma atividade não pode ser conduzida sem indivíduos, assim como indivíduos não podem conduzir atividades sem os mediadores sociais. Na TA o individual e o coletivo são vistos de forma dialética, onde para se compreender uma atividade coletiva é necessário levar em consideração ações individuais, ao mesmo passo que para compreender uma ação individual é necessário levar em conta o objeto que está sendo socialmente estabelecido, os instrumentos que são construídos social e historicamente como mediadores sociais, as regras e a divisão do trabalho que medeiam as relações entre os indivíduos da comunidade.

Devido ao fato de os objetos de atividades serem socialmente construídos na história da atividade, eles são, por um lado, dados aos indivíduos a priori e, por outro, interpretados e reconstruídos pelos mesmos indivíduos. O aspecto ideal do objeto, isto é, o conhecimento sobre o objeto e seus significados, é entendido e definido em diferentes épocas e por diferentes atores de diversas maneiras.

Baseado em Vygotsky (1978) e Leontyev (1981), Engeström (1987) desenvolveu um modelo de sistema de atividade o qual representa os relacionamentos básicos em sistemas de mediação da atividade humana. O modelo proposto descreve os processos de mediação cultural: produção, distribuição e troca, os quais estão presentes em todas as atividades coletivas e que, por sua vez, ocorrem em uma atividade. Nesse modelo, Engeström (1987) amplia o triângulo individual de mediação, diferentemente do proposto por Vygotsky, incorporando mediadores sociais organizacionais, tais como regras, divisão do trabalho e comunidade (Figura 2).

Engeström (1987) considera que a compreensão das ações individuais só é possível se houver a concepção de que o objeto da atividade está em constante relacionamento com sujeito, objeto e instrumento, assim como com os mediadores sociais. Comunidade refere-se àqueles que tomam parte na realização do objeto, regras referem-se a normas explícitas e convenções que restringem a ação dentro do sistema de atividade e divisão do trabalho refere-se à divisão de tarefas entre os indivíduos da comunidade. Os componentes do sistema de atividade estão sendo constantemente construídos e renovados em consequência do desenvolvimento de novas contradições.

Segundo Engeström (2001), um sistema de atividade tem vozes múltiplas (multivoicedness), ou seja, ele é formado por uma comunidade na qual os sujeitos têm múltiplos pontos de vista, tradições e interesses. A divisão do trabalho em uma atividade cria posições diferentes para os participantes, nas quais onde eles e os artefatos empregados carregam consigo sua história, regras e convenções. Essas vozes múltiplas podem ser tanto uma fonte de problemas quanto uma fonte de inovação, exigindo ações de entendimento e negociação.

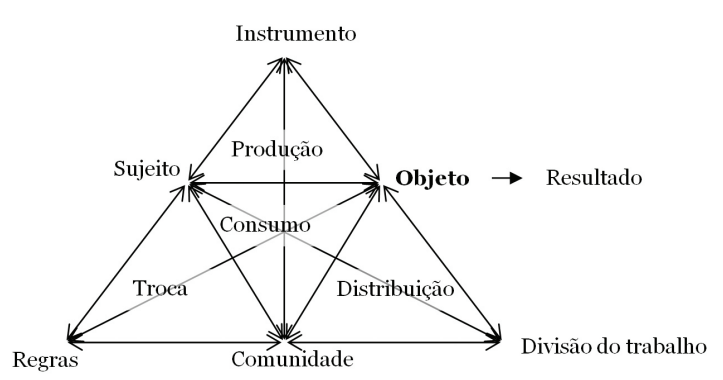

O modelo do sistema de atividade

Figura 2. O modelo do sistema de atividade. Fonte: Engeström (1987, p. 78). 


\section{Aprendizagem Expansiva}

Nesta seção apresenta-se a Teoria da Aprendizagem Expansiva, cujo interesse é representar o processo no qual os sujeitos constroem um novo objeto e o conceito para sua atividade coletiva, ou seja, no aprendizado expansivo os sujeitos aprendem o que ainda não existe (ENGESTRÖM, 1987, 2001).

Para expandir o objeto da atividade, o sujeito necessita também criar novas ferramentas e formas de organização social do trabalho em torno desse novo objeto. Aprender de forma expansiva implica a concepção e a implementação de um novo conceito de atividade, que envolve a reconstrução de todos os elementos dentro de um sistema de atividade (ENGESTRÖM; SANNINO, 2010).

Quando reflete sobre a lógica do desenvolvimento do sistema, o sujeito forma uma ideia inicial do conceito, que começa como uma explicação abstrata dele, uma "célula germinal" que é gradualmente enriquecida e transformada em um sistema concreto. O aprendizado envolve não só a formação de conceitos teóricos mas também a sua materialização. Em outras palavras, nesse processo, conceitos e ideias são enriquecidos para a obtenção de uma melhor compreensão do sistema. Aprender envolve a formação e a utilização de diferentes tipos de artefatos culturais, tais como modelos, conceitos e teorias, que ajudam a compreender o assunto e a construir o sistema teoricamente e na prática.

A Aprendizagem Expansiva visa superar uma contradição que leva a atividade a uma situação de crise. A expansão do objeto exige um modo de compreender as contradições internas do sistema e de encontrar possibilidades de continuar a desenvolvê-lo. Para captar a sua essência, o sujeito precisa compreender a lógica do seu desenvolvimento, e isso é possível através da análise de sua formação histórica, das contradições existentes nos ambientes organizacionais e das formas de superação/resolução dessas contradições.

Engeström (1987) discerne quatro níveis ou camadas de contradições: primária, secundária, terciária e quaternária. Os três últimos níveis são expressões externas ou manifestações da contradição primária. De acordo com Engeström, a contradição entre valor de uso e valor de troca, característica das mercadorias, está presente em todos os elementos de um sistema de atividade.

Distúrbios, dilemas e conflitos são manifestações das contradições. Embora contradições básicas não possam ser permanentemente resolvidas, elas podem assumir diferentes formas em diferentes atividades e tempos. Cada atividade experimenta contradições de diferentes maneiras. Na Teoria da Aprendizagem Expansiva, contradição é entendida como tensões entre elementos de um sistema de atividade, assim como entre sistemas de atividade. Contradições são consideradas a força motriz de transformação, favorecendo a tornar o objeto em movimento.

Engeström (1987) propõe um modelo ideal do ciclo de Aprendizagem Expansiva (Figura 3), o qual consiste numa representação gráfica de uma sequência de ações epistêmicas que ocorrem durante o aprendizado expansivo. Esse ciclo propõe que a emergência de um objeto novo e mais expandido começa dentro de uma atividade já consolidada, que começa a presenciar problemas. Essa fase é caracterizada por uma situação de insatisfação com a situação existente, um estado de crise ou uma necessidade urgente de fazer algo, e é chamada de "estado de necessidade", no qual as contradições aparecem em sua forma básica, como contradições primárias. Durante essa fase, os sujeitos começam a discutir e a desafiar o propósito da sua atividade (seu objeto) e a forma atual de alcançá-lo, por exemplo, métodos e tecnologias. Há uma necessidade de mudança, mas ainda não há uma pressão urgente de mudança, pois é possível deixar a situação como ela está (ENGESTRÖM, 1987).

A segunda fase é caracterizada pelo agravamento dos problemas já existentes na fase anterior. Distúrbios começam a ameaçar a obtenção dos resultados desejáveis. Essa fase é chamada de vínculo duplo. A expressão popular "estar de mãos e pés atados" pode auxiliar no entendimento do termo inglês para a palavra vínculo duplo: double-bind. Nela, a contradição começa a produzir desajustes e tensões entre os elementos do sistema de atividade que são chamadas contradições secundárias. Pessoas que participaram da atividade sentem que não é possível continuar a fazer as coisas da maneira atual, mas elas ainda não sabem o que deve ser feito para resolver os problemas (ENGESTRÖM; SANNINO, 2012).

$\mathrm{O}$ agravamento dos problemas leva à busca de soluções. Essas soluções podem ou não incluir um objeto mais expandido. Essas mudanças podem ser simplesmente ajustes nos elementos do sistema de atividade, como uma nova tecnologia ou uma nova maneira de fazer algo. Se a crise é grave o suficiente, as pessoas podem desafiar todo o sistema, inclusive o propósito de toda a atividade (o objeto). Se as pessoas desafiam e mudam o objeto da atividade, redesenhando-o de uma forma mais expansiva, o ciclo é chamado de "ciclo expansivo". Essa fase é intitulada de "objeto" ou "construção de um novo motivo". Nela, a comunidade projeta uma nova atividade na qual o objeto é mais expandido, ou seja, mais amplo, já que inclui características mais desejáveis do que o anterior.

Quando a solução é modelada, a atividade idealizada pode ser implementada. Essa fase é chamada de "aplicação" ou "generalização" (implementação). Nela, a comunidade começa a materializar os planos e pode dar início às primeiras tentativas de começar 


\section{Ciclo Geral do Desenvolvimento Expansivo}

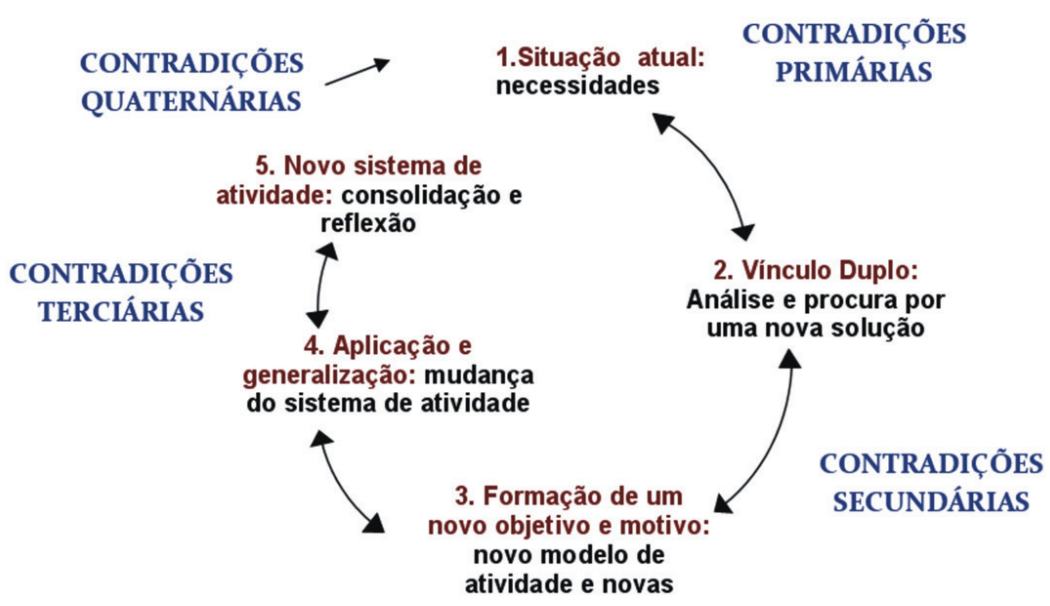

Figura 3. O ciclo de Aprendizagem Expansiva. Fonte: Engeström (1987, p. 322).

a produção do objeto idealizado. Tensões entre os elementos da nova atividade e elementos da atividade anterior começam a surgir (contradições terciárias). Esses desajustes podem ser causados tanto pelo desenvolvimento insuficiente dos novos elementos (que não são adaptados às novas condições porque os sujeitos não podiam prever totalmente toda a realidade) quanto por alguma incompatibilidade entre o novo e o velho. Esse tipo de contradição surge normalmente durante a fase de aplicação e generalização de uma nova atividade (Engeström, 1987).

Uma vez que a nova atividade começa a tomar forma, e o novo conceito da atividade começa a ser implementado e produzido, é muito provável que a nova atividade possa colidir com outras atividades relacionadas que ainda seguem a velha lógica de produção. Assim, antes de ser capaz de consolidar a nova atividade, o sujeito tem de resolver essas tensões com as atividades relacionadas. Essas tensões são as contradições quaternárias. Se os sujeitos vinculados à atividade conseguem resolver essas tensões, a atividade evolui para a fase de consolidação. Como Engeström e Sannino (2010) sugerem, o ciclo da Aprendizagem Expansiva não é uma fórmula idealizada das fases ou etapas. Na vida cotidiana, é provável encontrar um processo que segue esse modelo ideal típico, mas aqui tratam-se de possibilidades e não de certezas.

\section{Zona de desenvolvimento proximal}

Um importante conceito na TA é o de zona de desenvolvimento proximal (ZDP), o qual serve para determinar as possibilidades de desenvolvimento futuro tanto de indivíduos quanto de atividades nas organizações. Vygotsky (1978) propõe que o aprendizado de novos artefatos culturais, assim como a colaboração com outros colegas ou pessoas com mais experiência ou conhecimentos, gera um potencial de desenvolvimento. Ao usar esses artefatos, as pessoas se tornam mais independentes do contexto imediato e abrem novas possibilidades de futuro para o desenvolvimento, tornando-se agentes proativos. Nesse sentido reconhecem-se as possibilidades desse conceito na compreensão de que o aprendizado coletivo gera um potencial de desenvolvimento que supera o nível de aprendizado individual.

Engeström (1987, p. 174) redefiniu o conceito de ZDP no nível de atividade coletiva. De acordo com o autor, a ZDP

[...] é a distância entre as ações atuais dos indivíduos e uma nova forma histórica de atividade social que pode ser gerada coletivamente como solução para uma situação de vínculo duplo potencialmente incorporada nas ações cotidianas".

A ideia principal de Vygotsky (1978) e de Engeström (1987) é que a ZDP é a distância entre o que pode ser alcançado no presente e o que pode também ser adquirido no futuro para que um problema seja resolvido. Para Vygotsky (1978), um problema é resolvido através da colaboração com outras pessoas e com o uso de ferramentas culturalmente mais avançadas. Para Engeström (1987), o problema é visto como uma contradição a ser resolvida em uma atividade coletiva, portanto não se faz uso apenas de novas ferramentas, mas de um novo objeto e de novas relações sociais. Engeström (2000) enfatiza, ainda, que a ZDP é um conjunto de possibilidades futuras 
que poderiam resolver a contradição presente. Tais soluções podem exigir ferramentas mais avançadas, a colaboração entre pessoas de uma mesma atividade ou mesmo a colaboração entre sistemas de atividade diversos.

\section{Uma proposta metodológica para estudos sobre aprendizagem}

Como alternativa às limitações metodológicas discutidas na introdução deste artigo, apresenta-se aqui a metodologia de pesquisa de desenvolvimento do trabalho (Development Work Research) - PDT cujas aplicações, como do método de pesquisa intitulado Laboratório de Mudança (PEREIRA-QUEROL; JACKSON FILHO; CASSANDRE, 2011), estão sendo úteis em vários contextos de pesquisa.

A PDT é um instrumento de diálogo e de colaboração para o desenvolvimento entre: (a) investigadores que trabalham no desenvolvimento do aparato teórico e metodológico como, por exemplo, os conceitos de aprendizagem expansiva e a metodologia de intervenção; (b) os investigadores que trabalham para o desenvolvimento de determinadas atividades (atividades de ensino, por exemplo); e (c) os profissionais envolvidos, tanto nos quadros técnicos e gerenciais quanto nos de trabalhadores.

Essa metodologia oferece ferramentas metodológicas que ajudam o pesquisador a identificar uma rede de atividades, de forma que os resultados e conclusões obtidos possam ser comparados e que, por sua vez, generalizações teórico-genéticas sejam realizadas. O conceito de objeto apresentado acima não é apenas uma ferramenta teórica mas também uma ferramenta metodológica. $\mathrm{O}$ estudo de uma atividade implica levar a sério tanto as ações locais de atores bem como a atividade coletiva em estudo. Além disso, implica ver a atividade como culturalmente mediada por artefatos e socialmente construída e em constante mudança histórica.

Conforme apresentado na Figura 4, o ciclo metodológico da PDT inicia-se a partir de um delineamento do sistema de atividade propenso a: (a) obter uma visão preliminar sobre sua natureza/ origem e os problemas vivenciados pelas pessoas envolvidas na atividade; (b) delinear o sistema de atividade sob investigação. Na prática, essa fase é necessária para melhor definir o problema e os objetivos da pesquisa e requer uma coleta e análise preliminar de dados.

Num segundo momento há uma análise da atividade, a qual está dividida em três subetapas: (a) análise histórica do objeto; (b) análise histórica dos conceitos; e (c) análise empírica atual. A análise histórica dos conceitos tem como proposta identificar os modelos e conceitos que empregam algum tipo de sistema de atividade ou que têm sido utilizados em quaisquer de suas fases de desenvolvimento. A ideia básica da análise é estabelecer as dimensões do desenvolvimento e identificar novas formas de produção potenciais e a ZDP em nível de conceitos gerais (PEREIRAQUEROL, 2011). O objetivo da análise histórica do objeto é descobrir as contradições que dão origem às transições de uma fase de desenvolvimento para outra.

A terceira fase é a formação de novos instrumentos. Os participantes do sistema de atividade sob investigação são estimulados a formular qualitativamente novos modelos do sistema de atividade para resolver as contradições observadas. Após a implementação dos novos instrumentos é muito provável que contradições terciárias apareçam. Isso significa que os participantes do sistema de atividade experimentam conflitos entre a antiga e a nova forma de fazer e pensar.

A quarta fase é registrar e apoiar a resolução das contradições terciárias entre a nova e a antiga atividade. A tarefa do pesquisador não é apenas registrar e apoiar os eventos que ocorrem como resultado da contradição, mas também rastrear e analisar possíveis soluções para os conflitos produzidos pelos participantes em suas ações diárias. Essa tarefa também pode exigir métodos etnográficos de coleta de dados. Finalmente, o resultado da pesquisa expansiva é relatado e avaliado.

\section{Contribuições à aprendizagem organizacional}

Conforme mencionado na introdução deste artigo, existe uma série de questões a serem mais bem discutidas sobre os elementos que compõem a temática da aprendizagem organizacional. O objetivo deste artigo foi introduzir alguns conceitos e princípios da TA que venham a contribuir na resolução dessas questões. Entretanto, o desafio aqui proposto é poder relacionar a Teoria da Aprendizagem Expansiva aos questionamentos oferecidos nas publicações sobre a temática e explicitados na introdução deste artigo.

- 1) Natureza do fenômeno da aprendizagem organizacional (ontológico): Os dilemas referentes à conceitualização do fenômeno da aprendizagem organizacional refletem o dualismo entre uma ontologia construtivista e uma positivista. De forma simplificada, os positivistas assumem a existência de objetos independentemente do sujeito que os interpreta, ou seja, é possível ter conhecimento puro dos fenômenos. Já os construtivistas argumentam que o que se sabe sobre o mundo são ideias construídas pelo sujeito. A TA vai um passo adiante fazendo uma diferenciação entre o objeto e sua representação (ILYENKOV, 1977). A representação ou a conceitualização que se estabelece sobre o mundo se forma por 


\section{O ciclo da metodologia de pesquisa de desenvolvimento do trabalho}
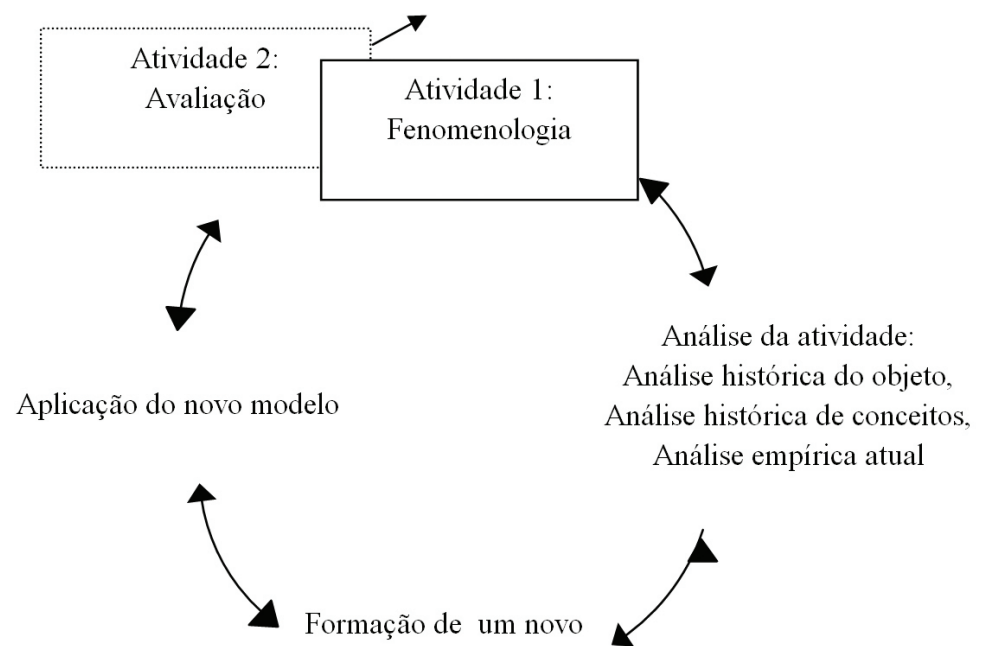

Formação de um novo modelo do Sistema de

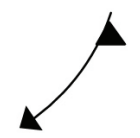
Atividade

Figura 4. Ciclo da metodologia de pesquisa de desenvolvimento do trabalho. Fonte: adaptado de Engeström (1987, p. 323).

meio da transformação desse objeto visando à satisfação de necessidades humanas. Para tanto, é através de atividades humanas, orientadas a objetos materiais, que o conhecimento é gerado (ILYENKOV, 1977).

Bitencourt e Azevedo (2006) questionam se a aprendizagem é cognitiva ou cultural. Como uma possível resposta, sugere-se que a TA não questione o fato de que o conhecimento é armazenado dentro da cabeça de indivíduos, pois o que ela questiona é que para que uma atividade seja conduzida e reproduzida esse conhecimento deve transferido de um indivíduo para outro, ou seja, isso requer que esse conhecimento seja materializado em artefatos culturais (p. ex.: verbalmente ou não). Nesse sentido, a aprendizagem é tanto cognitiva quanto cultural.

Em relação à dúvida se a aprendizagem é resultado ou processo (ANTONELLO; GODOY, 2009, 2010; RUAS; ANTONELLO, 2003), assume-se que, para a dialética materialista, a compreensão de um fenômeno requer a análise do seu movimento de formação e transformação, estudando-se as contradições que provocam mudanças. Transformando os objetos, o sujeito adquire conhecimento sobre as propriedades e funções deles e dessa forma produz generalizações que devem ser materializadas em símbolos e instrumentos para que possam ser transmitidas e para que a atividade seja reproduzida. A relação entre processo e resultado tem de ser vista de forma dialética, ou seja, um não existe sem o outro, são partes de uma mesma unidade em busca da transformação de objetos para alcançar certo resultado.
Bitencourt e Azevedo (2006) discutem se o aprendizado é tácito ou explícito. A diferenciação entre conhecimento tácito (conhecimento que não pode ser verbalizado) e explícito (aquele que pode ser expressado verbalmente) se torna problemática, pois o conhecimento nunca é puramente tácito ou puramente explícito, porque ele pode ser transmitido sem ser necessariamente uma comunicação formalizada. O conhecimento está no processo de transformação das atividades, portanto pode ser direta ou indiretamente expressado. Portanto, é mais real falar sobre conhecimento como embutido em ações e atividades, como algo que está constantemente fluindo entre pessoas, objetos e artefatos.

\section{- 2) Forma de conhecer esse fenômeno} da aprendizagem organizacional (epistemológico): No campo da AO reconhece-se a necessidade de se expandir a unidade de análise do nível individual para o nível interpessoal (ANTONELLO; GODOY, 2010; RUAS; ANTONELLO, 2003). Esse reconhecimento leva ao surgimento de um dilema: compreender se é o indivíduo ou se é a organização que aprende.

Os níveis de aprendizado propostos por Bateson (1972) auxiliam na explicação desse dilema. De acordo com esse autor, o nível de aprendizagem I corresponde a mudanças na forma como o sujeito (ator) utiliza um instrumento ou uma ferramenta sobre o objeto. Nesse tipo de aprendizagem, tanto o objeto como o instrumento são dados. Os principais instrumentos utilizados na aprendizagem I são chamados ferramentas - que são entendidas como uma 
incorporação generalizada de operações que se tornam padronizadas através da repetição. A aprendizagem II é uma mudança no processo de aprendizagem I, mudança na representação de uma maneira de realizar uma tarefa, representações reflexivas que incorporam formas de ação. Essa se aproxima da ideia de estruturas cognitivas, as quais podem ser concretizadas em artefatos como modelos, teorias, gráficos. A aprendizagem III é uma mudança no sistema de conjuntos de alternativas a partir do qual a escolha é feita. Na aprendizagem III, o problema em si tem de ser criado, e o sujeito reconhece a si mesmo como parte do sistema que tem de ser mudado.

Engeström (1987) diferencia o aprender II em dois tipos: o aprendizado IIa, que ele chama de aprendizagem reprodutiva; e a aprendizagem IIb, que chama de experimentação produtiva. Segundo ele, em aprendizagem IIa o objeto/resultado é dado e o instrumento é encontrado de forma aleatória (tentativa e erro) entre os instrumentos já conhecidos. Na aprendizagem IIb, o objeto/resultado é dado e os instrumentos, encontrados através da experimentação. $\mathrm{Na}$ aprendizagem II, o indivíduo autoavalia conscientemente o sucesso e fracasso de suas tentativas. Na aprendizagem II, o problema é dado e não envolve uma contestação do contexto (ENGESTRÖM, 1987). Para Engeström, a principal diferença entre as aprendizagens II e III é que na primeira o problema é dado enquanto que na segunda o problema deve ser construído. Inspirado por diferentes abordagens, Engeström (1987) propõe que o ponto de partida da aprendizagem III é uma contradição a partir de aprendizagem II. Além disso, há uma mudança fundamental na forma de aprender II e aprender III, na qual o sujeito deixa de ser um indivíduo e é substituído por um sujeito coletivo capaz de lidar com uma complexidade. Na aprendizagem III, o sujeito domina o sistema de sua atividade como um todo em termos de passado, presente e futuro. $O$ conceito Aprendizagem Expansiva se refere à criação de um novo conceito de objeto da atividade.

$\mathrm{Na}$ TA, Aprendizado Expansivo refere-se a reconceitualização do objeto da atividade, o qual direciona as ações dessa atividade e, consequentemente, também a reconceitualização dos outros elementos do sistema de atividade.

Conforme explicado anteriormente, na TA, a relação entre o indivíduo e o coletivo é dialética. Ações individuais são parte de atividades coletivas, assim como atividades coletivas são formadas por ações individuais. Portanto não existe aprendizado puramente individual nem puramente coletivo. Mesmo em ações individuais, o indivíduo usa artefatos que foram criados socialmente e sua ação é direcionada a um objeto coletivo. Da mesma forma, o coletivo não existe sem indivíduos, pois a atividade coletiva é formada pela ação dos indivíduos. O aprendizado coletivo não pode ocorrer sem mudar indivíduos, assim como mudanças nos indivíduos não podem ocorrer sem mudarem os artefatos culturais e mediadores sociais que esses indivíduos usam em suas ações.

$\mathrm{Na}$ ontologia dialética, a compreensão da aprendizagem organizacional deixa de ser observada como um modelo prescritivo de "como se aprende" e passa para uma compreensão baseada na identificação das contradições que levaram à origem de um determinado sistema. Nessa ontologia, a generalização de conceito, por exemplo, não se baseia no que há de comum entre o fenômeno estudado e os demais casos, mais sim em sua capacidade de resolver contradições semelhantes. Por exemplo, a produção de biogás tanto na região de Vehma, na Finlândia, como na região sudoeste de Santa Catarina, Brasil, surgiu como uma resolução para uma contradição inerente à produção de suínos, entre aumentar o volume de produção de suínos e a conservação ambiental (PEREIRA-QUEROL, 2011; PEREIRA-QUEROL; SEPPÄNEN, 2009; PEREIRA-QUEROL; SUUTARI; SEPPÄNEN, 2010). Apesar das diferentes condições locais, tais como culturais, políticas e climáticas, existe uma semelhança entre os casos em relação às contradições enfrentadas durante o desenvolvimento do sistema de produção de biogás. A generalização das soluções encontradas em cada caso é baseada nas contradições que afetam cada sistema.

No que se refere a conflitos, como sugerido por Antonello e Godoy (2009), eles exercem um papel importante na aprendizagem e no desenvolvimento de organizações e, portanto, devem ser vistos como oportunidades de aprendizado. Na TA, conflitos, distúrbios, rupturas, inovações, dilemas são compreendidos como expressões de contradições entre e dentro de sistemas de atividade, e, portanto, são precondições para que a Aprendizagem Expansiva ocorra. Aprendizagem é aqui entendida como permeada por contradições e, portanto, para o seu entendimento consideram-se cruciais a sua compreensão tanto epistemológica (explicando aprendizagem) como metodológica (facilitando o aprendizado organizacional).

- 3) Métodos para apreender esse fenômeno organizacional (metodológico): A metodologia do PDT, assim como aplicações da mesma, por exemplo, o Laboratório de Mudança (PEREIRAQUEROL; JACKSON FILHO; CASSANDRE, 2011) vão de encontro à necessidade apontada por Bitencourt e Azevedo (2006), os quais enfatizam representar, avaliar e facilitar a aprendizagem.

Em abordagens teóricas tradicionais sobre a AO, o que deve ser aprendido geralmente é imposto de cima para baixo, ou de fora da atividade para dentro, por exemplo, consultores ou especialistas 
na área propõem soluções prontas ou preexistentes. Já na TA são os próprios sujeitos que, com a ajuda do intervencionista/pesquisador, analisam as contradições inerentes a sua própria atividade e desenham um novo modelo para ela utilizando recursos próprios e outros recursos oferecidos pelo intervencionista ou pesquisador, tais como o modelo teórico-metodológico de ZDP. Portanto, na TA, o papel do intervencionista não é impor soluções mas sim oferecer recursos para que os próprios sujeitos reconheçam a contradição, superem-na para que a aprendizagem ocorra, instigando-os a novas reflexões que possam sugerir transformações tanto nas suas atividades como neles mesmos.

\section{Considerações finais}

Para a construção teórica deste artigo foram considerados alguns trabalhos já existentes e, ao mesmo tempo, teve-se a pretensão de ultrapassá-los em alguns pontos fundamentais.

Nesse sentido, compreende-se que a TA possui em seu escopo uma composição teórico-metodológica capaz de pensar a organização como um fenômeno histórico, complexo, concreto, em movimento e dialético, rompendo-se assim com leituras formais, prescritivas e abstratas do fenômeno organizacional.

Por sua vez, essa teoria abrange a aprendizagem enquanto prática coletiva, contraditória e situada social e historicamente e cujos sujeitos que a vivenciam são os responsáveis pela sua concretização, rompendo-se assim com métodos objetivistas e naturalistas.

Para tanto, a TA pode contribuir para se pensar a aprendizagem vinculada com o desenvolvimento e não dicotomicamente e, para que isso aconteça, sugere-se uma metodologia intervencionista capaz de oferecer ferramentas para a inovação a partir do próprio processo de pesquisa.

Finalmente, almeja-se que as reflexões trazidas neste artigo sejam indicadoras de novos olhares sobre a aprendizagem organizacional, no compasso e no descompasso que são próprios do movimento de construção do pensamento dialético também presente na prática da pesquisa científica.

\section{Agradecimentos}

Agradecemos o apoio da Academia da Finlândia (Academy of Finland), projeto número 253804, e da Capes (processo número 8606/11-0) na realização deste trabalho.

\section{Referências}

ANTONELLO, C. S.; GODOY, A. S. Uma agenda brasileira para estudos em aprendizagem organizacional. Revista de Administracao de Empresas, v. 49, n. 3, p. 266-281, 2009.
ANTONELLO, C. S.; GODOY, A. S. A Encruzilhada da aprendizagem organizacional: uma visão multiparadigmática. Revista de Administração Contemporânea, v. 14, n. 2, p. 310-332, 2010. http:// dx.doi.org/10.1590/S1415-65552010000200008

BATESON, G. Steps to an ecology of mind. London: University of Chicago Press, 1972.

BENSON, J. K. Les organisations: un point de vue dialectique. In: SÉGUIN, F.; CHANLAT, J.-F. L'analyse des organisations une anthologie sociologique. Tome I: Les théories des organisations. Montréal: Gaëtan Morin, 1983.

BITENCOURT, C. C.; AZEVEDO, D. O Futuro da Aprendizagem Organizacional: possibilidades e desafios. Revista de Administração de Empresa, v. 46, p. 110-112, 2006.

CAMARGO, D. Emoções no processo de aprendizagem. 1997. Tese (Doutorado)-Universidade Católica de São Paulo, São Paulo, 1997.

CASSANDRE, M.; BULGACOV, Y. L. M.; CAMARGO, D. O conceito de prática a partir da perspective da teoria da atividade. In: COLÓQUIO DE EPISTEMOLOGIA E SOCIOLOGIA DA CIÊNCIA DA ADMINISTRAÇÃO, 1., 2011, Florianópolis. Anais... Florianópolis: ORD/UFSC, 2011.

COLE, M. Cultural Psychology: A once and future discipline. London: Belknap Press, 1996.

DAVYDOV, V. Types of Generalization in Instruction: Logical and psychological problems in the structuring of school curricula. Reston: National Council of Teachers of Mathematics, 1990.

ENGESTRÖM, Y. Expansive learning at work: Toward an activity-theoretical reconceptualization. Journal of Education and Work, v. 14, n. 1, p. 133-156, 2001. http://dx.doi.org/10.1080/13639080020028747

ENGESTRÖM, Y. Learning by expanding. An activitytheoretical approach to developmental research. Helsinki: Orienta-Konsultit Oy, 1987.

ENGESTRÖM, Y. Activity theory as a framework for analyzing and redesigning work. Ergonomics, v. 43, n. 7, p. 960-974, 2000. PMid:10929830. http://dx.doi. org/10.1080/001401300409143

ENGESTRÖM, Y.; SANNINO, A. Studies of expansive learning: Foundations, findings and future challenges. Educational Research Review, v. 5, n. 1, p. 1-24, 2010. http://dx.doi.org/10.1016/j.edurev.2009.12.002

ENGESTRÖM, Y.; SANNINO, A. Whatever happened to process theories of learning? Learning, Culture and Social Interaction, v. 1, n. 1, p. 45-56, 2012. http:// dx.doi.org/10.1016/j.lcsi.2012.03.002

FARIA, J. H. Economia política do poder: os fundamentos da teoria crítica nos estudos organizacionais. Curitiba: Juruá, 2007. v. 3.

ILYENKOV, E. V. Dialectical Logic: Essays in its history and theory. Translation HC Creighton. Moscow: Progress, 1977.

ILYENKOV, E. V. The dialectics of the abstract and the concrete in Marx's 'Capital'. Moscow: Progress, 1982.

LEONTYEV, A. N. Activity, consciousness, and personality. Englewood Cliffs: Prentice-Hall, 1978. 
LEONTYEV, A. N. Problems of the development of the mind. Moscow: Progress, 1981.

MARX, K. Capital: a critique of political economy. London: Penguin Classics, 1976.

MIETTINEN, R. Object construction and networks in research work: The case of research on cellulosedegrading enzymes. Social Studies of Science, v. 28, n. 3, p. 423-463, June 1998. http://dx.doi. org/10.1177/030631298028003003

MIETTINEN, R. Object of activity and individual motivation. Mind, Culture and Activity, v. 12, n. 1, p. 52-69, Feb. 2005. http://dx.doi.org/10.1207/ s15327884mca1201_5

MIETTINEN, R.; SAMRA-FREDERICKS, D.; YANOW, D. Re-turn to practice: an introductory essay. Organization Studies, v. 30, n. 12, p. 1309-1327, 2009. http://dx.doi. org/10.1177/0170840609349860

PEREIRA-QUEROL, M. A. Learning Challenges in Biogas Production for Sustainability: An activity theoretical study of a network from a swine industry chain. 2011. 256 f. Dissertation (Doctoral)-Institute of Behavioural Science, Studies in Educational Sciences, Helsinki, 2011.

PEREIRA-QUEROL, M. A.; SEPPÄNEN, L. Learning as changes in activity systems: The emergence of on-farm biogas production for carbon credits. Outlook on Agriculture, v. 38, n. 2, p. 147-155, 2009. http:// dx.doi.org/10.5367/000000009788632359

PEREIRA-QUEROL, M. A.; SUUTARI, T.; SEPPÄNEN, L. Learning as the construction and re-mediation of activity systems: environmental management in biogas production. Journal of Agricultural Education and Extension, v. 16, n. 4, p. 373-384, 2010. http://dx.doi. org/10.1080/1389224X.2010.515059

PEREIRA-QUEROL, M. A.; JACKSON FILHO, J. M.; CASSANDRE, M. P. Change Laboratory: uma proposta metodológica para pesquisa e desenvolvimento da aprendizagem organizacional. Revista RAEP - Administração: Ensino e Pesquisa, v. 12, n. 4, p. 609-640, out./dez. 2011.

RUAS, R.; ANTONELLO, C. S. Repensando os referenciais analíticos em aprendizagem organizacional: uma alternativa para análise multidimensional. Revista de Administração Contemporânea, v. 7, n. 3, p. 203-212, jul./set. 2003. http://dx.doi.org/10.1590/ S1415-65552003000300011

SANNINO, A. Activity theory as an activist and interventionist theory. Theory \& Psychology, v. 21, n. 5, p. 571-597, 2011. http://dx.doi. org/10.1177/0959354311417485

TOLMAN, C. The metaphysic of relations in riegel, klaus dialectics of human-development. Human development, v. 24, n. 1, p. 33-51, 1981. http://dx.doi. org/10.1159/000272623

VIRKKUNEN, J. Two theories of organizational knowledge creation. Learning and Expanding with Activity Theory, p. 144-159, 2009.

VIRKKUNEN, J.; SCHAUPP, M. From change to development: Expanding the concept of intervention. Theory \& Psychology, v. 21, n. 5, p. 629-655, 2011. http://dx.doi.org/10.1177/0959354311417486

VIRKKUNEN, J.; RISTIMÄKI, P. Double Stimulation in Strategic Concept Formation: An Activity-Theoretical Analysis of Business Planning in a Small Technology Firm. Mind, Culture, and Activity, v. 19, n. 3, p. 273-286, 2012. http://dx.doi.org/10.1080/1074903 9.2012.688234

VYGOTSKY, L. S. Mind and Society: The development of higher mental processes. Cambridge: Harvard University Press, 1978. 